\title{
Desertifying deserts
}

\begin{abstract}
Authors:
Jaime Martínez-Valderrama ${ }^{\mathrm{a}, 1}$, Emilio Guirado ${ }^{\mathrm{a}} \&$ Fernando T. Maestre $^{\mathrm{a}, \mathrm{b}}$
\end{abstract}

anstituto Multidisciplinar para el Estudio del Medio “Ramón Margalef”, Universidad de Alicante, Carretera de San Vicente del Raspeig s/n, 03690 San Vicente del Raspeig, Alicante, Spain.

${ }^{\mathrm{b}}$ Departamento de Ecología, Universidad de Alicante, Carretera de San Vicente del Raspeig s/n, 03690 San Vicente del Raspeig, Alicante, Spain.

${ }^{1}$ To whom correspondence should be addressed: Email: jaime.mv@ua.es

The current definition of desertification excludes hyper-arid zones, given their lack of economic activity. However, the 101 million people living there, ongoing land degradation associated with the use of groundwater for intensive agriculture and climate-changeinduced aridity call for a revision of this definition.

The United Nations (UN) Decade for Deserts and the Fight against Desertification comes to an end in 2020. Although deserts and desertification tend to go hand in hand in the public imagination, it is important to clarify their differences. Deserts are mature ecosystems with very low productivity due to severe water limitations promoted by low rainfall and high evapotranspiration levels, and have evolved under this state over a long period ${ }^{1}$.

Desertification deprives land of its capacity to support life and to provide essential ecosystem services to human populations, leading to displacement of populations. The UN Convention to Combat Desertification (UNCCD) defines desertification as "land degradation in arid, 
semi-arid and dry sub-humid areas resulting from various factors including climatic variation and human activity"2. This definition, widely used by scientists and policy makers alike, circumscribes the problem to those territories where the aridity index (AI) -the ratio between mean annual precipitation and mean annual potential evapotranspiration- is between 0.05 and 0.65 , roughly $31 \%$ of Earth's surface ${ }^{3}$. Land degradation in drylands is a key environmental problem that compromises the livelihoods of more than 1 billion people globally, mainly in developing countries ${ }^{4}$.

The consolidation of the UNCCD definition of desertification required decades. This definition was an important conceptual breakthrough because it broadened the causes from being exclusively climatic to include the impacts of human activities. Despite its value and the important role it has played in fostering our understanding of desertification, this definition is not free from problems. A major inconsistency was to exclude hyper-arid lands (Figure 1a), which account for $17.2 \%$ of drylands worldwide ${ }^{3}$ or $6.4 \%$ of Earth's surface (i.e. over 9.5 million $\mathrm{km}^{2}$, almost the area of Europe). They were excluded because it was assumed that it is impossible to carry any economic activity in these harsh environments and, consequently, they are mostly uninhabited. Hence, degradation in hyper-arid areas would be driven by climatic variations, precluding their desertification according to the official definition of the UNCCD. This is in line with the common view that hyper-arid zones are already deserts, and therefore cannot be desertified ${ }^{5}$. 


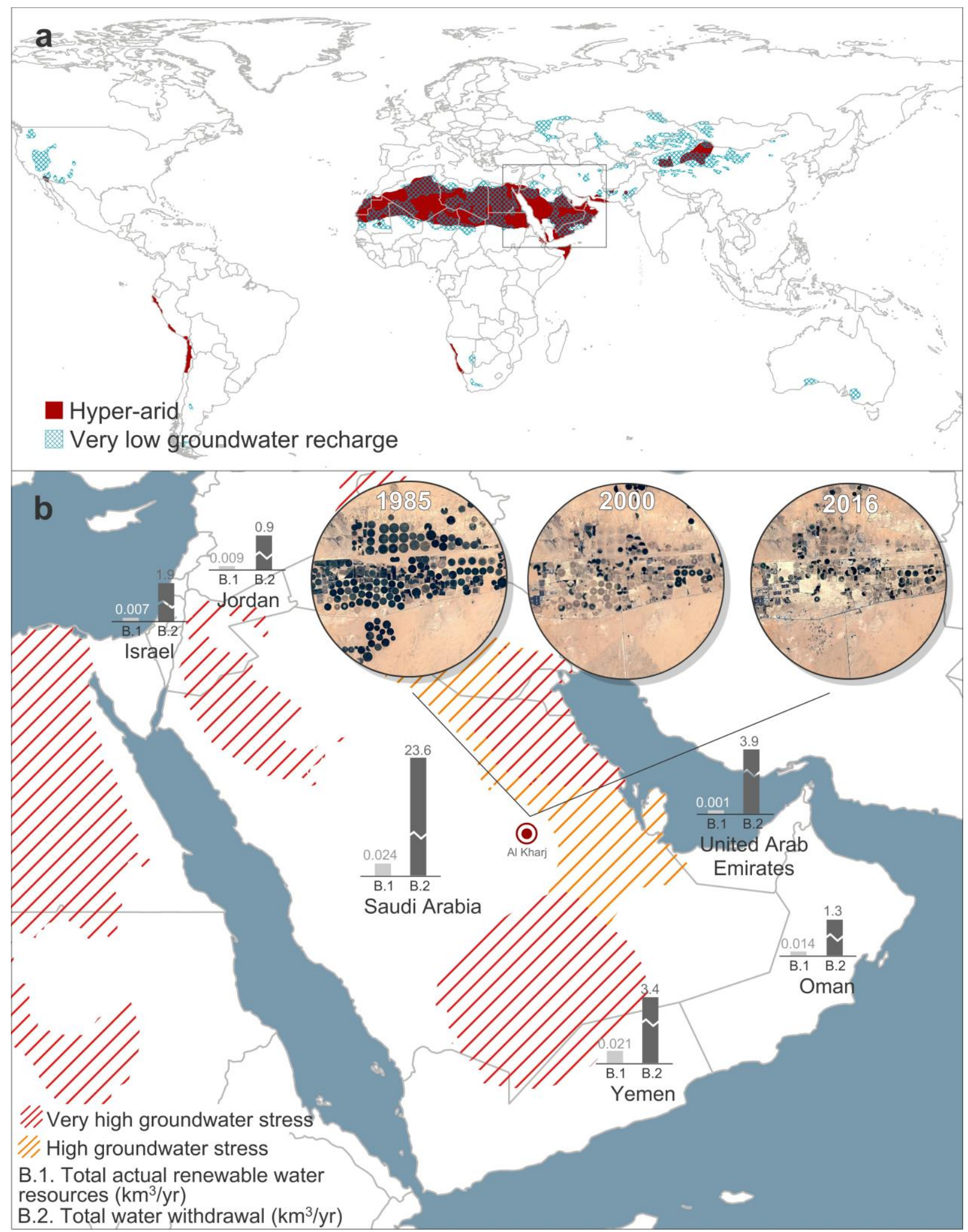

Figure 1. (a) Global distribution of hyper-arid areas and aquifers with very low recharge rate ( $<2 \mathrm{~mm} /$ year), according to World-wide Hydrogeological Mapping and Assessment

Programme (https://www.whymap.org/whymap/EN/Maps_Data/Gwr/gwr_node_en.html). (b) 
Status of groundwater bodies in the Middle East ${ }^{19}$ and some water balances by country ${ }^{12}$. The inset figures show a sequence of abandonment of crop circles after aquifer exhaustion in $\mathrm{Al}$ Kharj, Saudi Arabia (red dot in the map; images obtained from the Landsat satellite).

\section{Including hyper-arid areas within the scope of desertification}

At least two facts question the exclusion of hyper-arid zones from the UNCCD definition of desertification. First, ongoing increases in aridity linked to climate change are expanding drylands globally and changing the relative size of each aridity category (dry sub-humid, semiarid, arid and hyper-arid). According to the World Atlas of Desertification ${ }^{3}$ (WAD), a comparison of the 1951-1980 and 1981-2010 periods shows that drylands have increased by about $0.35 \%$ globally. The figure is probably higher, as this analysis excludes the five hottest years on record (2015 to 2019) ${ }^{6}$. Specifically, data from the WAD reveal that hyper-arid areas have increased by $0.09 \%$ as a result of the aridification of arid zones worldwide. Regional studies in China (where aridity has increased over $75.9 \%$ of its land area during the period $\left.1961-2016^{7}\right)$ and Pakistan $\left(0.52 \%\right.$ increase in hyper-arid lands during the period $\left.1901-2016^{8}\right)$, and global estimates of changes in aridity $^{9}$ point in the same direction. Furthermore, current forecasts indicate that hyper-arid areas will grow to occupy 8.4-12.6\% of Earth's total surface by the end of this century due to climate change-induced increases in aridity ${ }^{10}$. Following the current UNCCD definition of desertification, these new hyper-arid lands are, by current definition, free of desertification. Second, hyper-arid areas are home to more than 100 million people (1.7\% of the world's population), most of whom live in $70,000 \mathrm{~km}^{2}$ of urban areas ${ }^{4}$. Many of these areas are in countries with population growth rates exceeding the world average. In addition, the livestock herds of nomadic populations have always grazed the dispersed vegetation of these territories, as grazed rangelands account for $97 \%$ of land use in 
hyper-arid lands ${ }^{4}$. Consequently, the lack of economic activity in these areas must be reconsidered.

Starting in the 1950s, major advances in geological knowledge, sinking of bores and wells, pump technology and rural electrification, together with cheap energy and very permissive -or nonexistent- regulations, laid the foundation for massive groundwater use in hyper-arid areas, which currently support more than $55,000 \mathrm{~km}^{2}$ of cultivated area worldwide ${ }^{4}$. Aquifer exploitation in these areas is regarded as groundwater mining because resource renewability is virtually nil. The exploitation of fossil groundwaters has made hyperarid areas such as the Saudi Desert bloom into verdant fields by tapping underground aquifers. In three decades, Saudi Arabia has consumed 600 billion $\mathrm{m}^{3}$ of water (Figure 2), became the $6^{\text {th }}$ largest global wheat exporter, and depleted its precious aquifers ${ }^{11}$. History repeats itself in most countries of the Middle East and other hyper-arid regions ${ }^{12}$. For example, in Jordan, Yemen, and the United Arab Emirates, 0.94, 3.40, and $3.99 \mathrm{~km}^{3}$ of water, respectively, are consumed annually. However, natural recharge only replenishes $0.01,0.006$, and $0.0003 \%$ of these extractions, respectively. Not even Israel escapes this pattern $\left(1.95 \mathrm{~km}^{3}\right.$ groundwater use; $0.006 \%$ of replenishment), demonstrating that being the world leader in using water efficiently does not prevent it from being trapped within the so-called Jevons $\operatorname{paradox}^{13}$ : "as technological improvement increases the efficiency with which a resource is used, an increase in the consumption of that resource is more likely than a decrease". These examples illustrate how having access to cutting-edge technology does not ensure a sustainable use of resources but rather may contribute to their depletion. Groundwater depletion can be found in other hyper-arid areas under increasing population pressure, such as North Africa or China. For example, high water demand is threatening oases in the region of Timimoun (Algeria), which have been in use for more than 1000 years ${ }^{14}$. Similarly, oases in the Taklamakan Desert (northwestern China), which are fed by melting Himalayan ice, are 
suffering from alarming agricultural expansion, while their recharge is declining due to global warming $^{15}$.

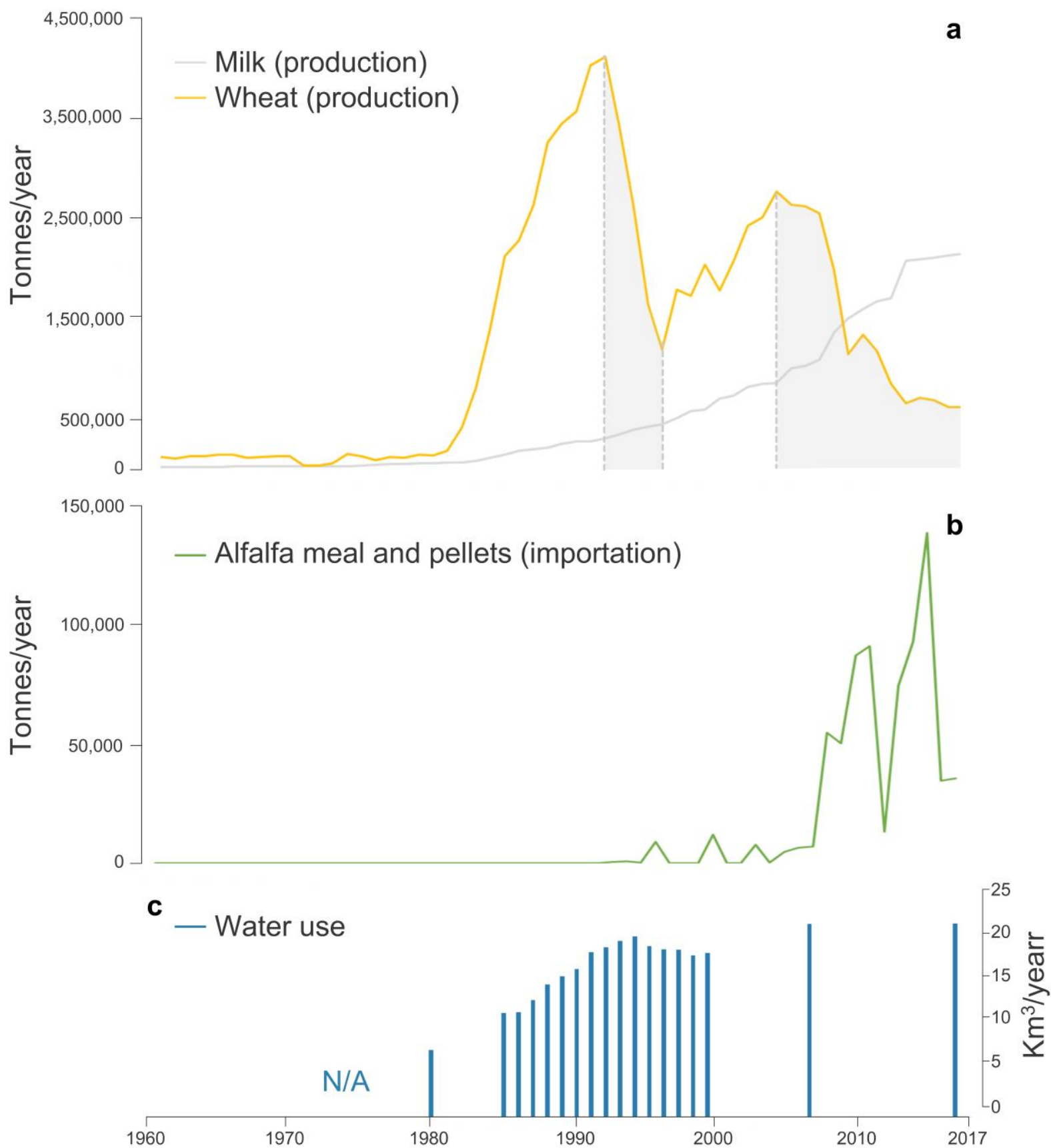

Figure 2. Wheat and cow fresh milk production (a), alfalfa meal and pellets imports (b) and groundwater use (c) in Saudi Arabia for the period 1960-2017 ${ }^{11,16}$. 


\section{Watering the desert}

Dairy farming in Saudi Arabia is one example of how technological advances can lead to markedly unsustainable water use in hyper-arid areas. Dairy has become a major industry in Saudi Arabia since 1998 and continues to grow, accounting for 3\% of its GDP. The strategic and legitimate notion of self-sufficiency began as an ambitious, seemingly impossible dream. Saudi Arabia sought to manufacture all of its products from milk produced by its own livestock, the needs of which would be covered by local crops. Notwithstanding the realities of a desert environment, the 365,000 heads of cattle being raised in Saudi Arabia produce $2,159,000 \mathrm{t}$ of fresh milk annually ${ }^{16}$. The amount of water to support this production system is astonishing and requires wells $150-1,500 \mathrm{~m} \mathrm{deep}^{17}$. In addition to crop irrigation, large quantities of water are needed for the dairy herd itself, as each milk-producing cow requires 75-110 1 of water per day. Water is also used for cooling the herd, and cattle pens are equipped with evaporative cooling systems. Water withdrawal has gradually increased to 20 $\mathrm{km}^{3}$ per year in Saudi Arabia (Figure 2c) and almost $30 \mathrm{~km}^{3}$ if we consider the Arabian Peninsula as a whole.

The exhaustion of the immense Arabian aquifer ${ }^{18}$ is manifested by various symptoms that indicate the onset of desertification. Immediate effects are water storage decline and land abandonment ${ }^{19}$. Satellite images show the migration of crop circles to areas where groundwater is still available, leaving a trail of ochre cultivation circles that blur the desert sand (Figure 1b). The decline in wheat production (Figure 2a), the ban on forage crop cultivation since 2016, the growing imports of alfalfa (Figure 2b), and the Saudi Arabian Initiative, a plan to seek "food security" by developing farm resources in land-rich, cash-poor countries around the world, confirm the collapse of an economic system that was established in an hyper-arid zone, and constitutes a clear example of desertification. 


\section{A call to rethink how we monitor and define desertification}

Overexploitation of water resources in hyper-arid lands fits perfectly into e concept of desertification: irreversible degradation of a vital resource driven by human activities. Along with a formal inclusion of hyper-arid areas in the UNCCD definition of desertification, it is necessary to refine the indicators used for monitoring desertification processes. For example, positive trends in net primary production in hyper-arid lands should warn about the emergence of irrigated areas. The assessment of these anomalies should be accompanied by the monitoring of groundwater use with tools such as the Gravity Recovery and Climate Experiment satellite mission ${ }^{19}$ combined with local knowledge and information (e.g. aquifer piezometric measurements, crop production and market statistics) to validate and interpret remote sensing data ${ }^{20}$. It is critical that we have evidence of aquifer exploitation in order to take early action to reduce the onset of desertification in hyper-arid areas.

Over the last few decades, desertification has not attracted as much public and scientific attention as other major environmental issues such as climate change and biodiversity loss. But as already emphasized by the former UN Secretary-General Kofi Annan back in 2005 “desertification is one of the world's most alarming processes of environmental degradation", and its negative impacts will be amplified by the ongoing process of aridification of our planet as a result of climate change ${ }^{10}$. It is thus time to rethink how we define desertification to better study and understand it. This is a critical step to improve the livelihood of more than one billion of the poorest people, and to ensure the sustainability of our planet. 


\section{Acknowledgments}

This work was funded by the European Research Council grant agreement $\mathrm{n}^{\circ} 647038$ (BIODESERT). FTM acknowledges support from Generalitat Valenciana (CIDEGENT/2018/041). The authors would like to thank David J. Eldridge for his valuable comments and revisions of the text.

\section{References}

1. Ward, D. The Biology of Deserts. (Oxford University Press, 2016).

2. UN (United Nations). United Nations Convention to Combat Desertification in Countries Experiencing Serious Drought and/or Desertification, Particularly in Africa. Document A/AC. 241/27, 12. 09. 1994 with Annexe. (1994).

3. Cherlet, M. et al. World Atlas of Desertification. (Publication Office of the European Union, 2018). doi:10.2760/9205

4. Millenium Ecosystem Assessment (MEA). Drylands. in Ecosystems and Human WellBeing: Scenarios (eds. Hassan, R., Scholes, R. \& Ash, N.) 623-662 (Island Press, 2005).

5. Safriel, U. L. Degrad. Dev. 20, 353-366 (2009).

6. WMO (World Meteorological Organization). July matched, and maybe broke, the record for the hottest month since analysis began. (2019).

7. Liu, L. et al. Int. J. Climatol. 39, 50-60 (2019).

8. Ahmed, K., Shahid, S., Wang, X., Nawaz, N. \& Khan, N. Hydrol. Earth Syst. Sci. 23, 3081-3096 (2019).

9. Lickley, M. \& Solomon, S. Environ. Res. Lett. 13, 1-12 (2018).

10. Huang, J., Yu, H., Guan, X., Wang, G. \& Guo, R. Nat. Clim. Chang. 6, 166-172 
(2016).

11. Elhadj, E. Camels Don't Fly, Deserts Don't Bloom: an Assessment of Saudi Arabia's Experiment in Desert Agriculture. Occasional Paper 48, (2004).

12. FAO (Food and Agriculture Organization of the United Nations). Irrigation in the Middle East region in figures. AQUASTAT Survey - 2008. (FAO, 2009).

13. Jevons, W. S. The Coal Question; An Inquiry Concerning the Progress of the Nation, and the Probable Exhaustion of Our Coal Mines. (Macmillan \& Co., 1866).

14. Remini, B., Achour, B. \& Albergel, J. Arab. J. Geosci. 4, 495-506 (2011).

15. Liu, Y. et al.Sustain. 10, 1-12 (2018).

16. FAO (Food and Agriculture Organization of the United Nations). FAOSTAT Statistical Database. (2019). Available at: fao.org/faostat/en/\#home. (Accessed: 25th October 2019)

17. Chowdhury, S. \& Al-Zahrani, M. J. King Saud Univ. - Eng. Sci. 27, 68-82 (2015).

18. Fallatah, O. A., Ahmed, M., Save, H. \& Akanda, A. S. Hydrol. Process. 31, 4081-4091 (2017).

19. Richey, A. S. et al. Water Resour. Res. 51, 5217-5237 (2015).

20. Cowie, A. L. et al. Environ. Sci. Policy 79, 25-35 (2018). 